tem, it appears amply demonstrated that the process, whether mild or severe, is etiologically and pathologically the same; that there are all gradations from a slight involvement of the bronchioles with adjacent alveolar infiltration to an extensive involvement of entire lobes simulating lobar pneumonia; and that the cases were mild or severe, depending on the resistance of the individual or variations in the virulence of the organism, rather than the accepted idea that pneumonia complicated one case and not another.

\section{ANTHRAX AT EMBARKATION HOSPITAL, NEWPORT NEWS, VA.}

\author{
OTIS T. AMORY, M.D. (VIRGINIA) \\ Captain, M. C., U. S. Army \\ AND \\ BENJAMIN RAPPAPORT, M.D. (ChICAGo) \\ Lieutenant, M. C., U. S. Army \\ NEWPORT NEWS, VA.
}

In view of the recent occurrence of anthrax in the various Army camps, an account of the cases observed at the Embarkation Hospital, Newport News, Va., should be of interest:

\section{REPORT OF CASES}

CAse 1.-History.-A soldier, admitted to the hospital, May 25,1918 , with the transfer diagnosis of mumps, had had headache, May 23, and then noticed a small papule on the left cheek. While shaving, he cut the papule, which bled freely. His face started to swell the same afternoon. Headache increased, then the throat began to swell, deglutition was painful, he had nausea and vomiting, and he felt very chilly. There was a nodule on the left cheek the size of a quarter, with a dark cherry eschar, with a well defined, elevated margin. The temperature was 102.6, the pulse 104, and respiration 28 . Two hours later the temperature was 103.4 . Anthrax bacilli were demonstrated in smears.

Operation.-May 25, the nodule was excised under local anesthesia, the base cauterized with pure phenol (carbolic acid), 5 per cent. phenol injected into the subcuticular tissue around the excised area, and a 95 per cent. alcoholic dressing kept continuously applied. The wound was dressed every twenty-four hours. The base was cauterized with pure phenol until the edema subsided, and then with 5 per cent. phenol until pure granulations developed. After twenty days, repeated culture failed to demonstrate bacilli, when, under local anesthesia, skin grafting was performed. The patient returned to duty, July 4 , with the wound healed.

Comment.-After the operation, the swelling increased for thirty-six hours, extending to the supraclavicular glands; there were no kidney complications. The temperature became normal, May 29, with, no subsequent rise. Medical treatment was given from a symptomatic standpoint. Aside from the smear, no laboratory work was done in this case.

CASE 2.-History.-A soldier, admitted, June 6, 1918, with the transfer diagnosis of parotitis, had noticed, two days prior, a papule on the right cheek, which he picked. Swelling began and very rapidly extended down the neck. There was a pustule, the size of a green pea, with a deeply indurated margin, rather blurred and studded with vesicles, and a dark cherry center. The induration was out of proportion to the nodule. There were no marked constitutional symptoms. A smear showed anthrax bacilli. The patient stated that he had been wearing a chinstrap which rubbed this papule. The temperature was 100.2 , the pulse 90 , and respiration 20 . June 8 , the temperature was 104.4 , the pulse 110 , and respiration 26 .

Operation.- June 6 , under local anesthesia, the nodule with an indurated area the size of a half dollar was excised, with the same after-treatment as in the preceding case. The patient's temperature of 104.4 , June 8 , gradually receded until it became normal, June 11. Skin grafting was performed,
July 5. The patient was returned to duty, August 3, with a very small area remaining unhealed.

Comment.-This was a normal case with rather marked swelling and great reaction following operation. The organisms in this case were obtained in both smear and culture.

CASE 3.-History.-A soldier, admitted, July 15, 1918, with undetermined diagnosis, had noticed a small papule, July 11, which itched. He scratched it several times that night. Next day, he noticed a small lump (induration). He ached all over as if he had the grip. The lesion itself was not very painful. The swelling increased. July 13 , he reported on sick call. He remained in quarters, July 14, and was sent to the hospital. Smear on admission was positive. $\mathrm{He}$ says he went on a hike, July 11 , and slept that night on some of his equipment, which put a leather strap against his cheek. July 11, he used a new shaving brush.

Findings.-On the right cheek, at the margin of the lower jaw, there was a black eschar about one-half inch: in diameter, with an induration about $1 \frac{1 / 2}{2}$ inches across. The eschar was surrounded by a yellowish border and numerous vesicles and edema involving the neck, chiefly on the right side. The temperature was 102.2 , the pulse 120 , and respiration 24 . July 16 , the temperature was 98 , the pulse 70 , and respiration 20. There was fever for only twelve hours after admission.

Operation.-July 15 , excision of the nodules the size of a silver dollar and the usual operative technic were carried out. Edema disappeared after five days. July 20, phenol was discontinued and physiologic sodium chlorid solution used. Edema reappeared; under phenol it again disappeared. August 18, phenol was discontinued and again the edema appeared, to disappear after the use of pheno1. September 19 , 40 c.c. of antianthrax serum were given subcutaneously with local swelling; September 23, 40 c.c. of antianthrax serum were given, and irritable heart developed. The patient complained severely, but no pathologic condition was produced. The serum was discontinued; local applications were continued; healthy granulations rapidly formed. At present the wound is practically healed.

Comment.-There was a very slight reaction following the operation. This case was a very stubborn one. On administration of anthrax serum, there was a local reaction about the site of the wound. Organisms were obtained from smear, culture, and the following tissues: from inoculated guineapig, blood stream, liver, heart, spleen, and site of inoculation. The guinea-pig died within thirty-six hours after inoculation.

CASE 4.-A soldier, admitted, Sept. 21, 1918, with the transfer diagnosis undetermined, had noticed a papule, the day before, on the left side of the face; next day there was edema on one side of the face, but very little pain. He reported on sick call and was sent to the hospital. He arrived at this camp, September 19. He slept on a leather seat and had been using a new shaving outfit, but destroyed it before coming to the hospital.

Findings.-Over the angle of the left side of the lower jaw was a black eschar about $2 \mathrm{~cm}$. in diameter, surrounded by a ring of small vesicles of a dirty dark yellow; there was induration about 1 inch across, and immense edema of the left side of the face, neck and the upper third of the chest. On admission, the temperature was 102 , the pulse 112 , and respiration 20 . After operation the temperature rose to 103.2 , the pulse 120 , and respiration 18 .

Operation.-September 21 , excision of the nodule the size of a silver dollar, with the usual technic, was carried out. In addition, 40 c.c. of serum were given. September 22 , edema increased, closing the left exe and involving the upper half of the chest; there was slight delirium. September 23 the edema was unchecked. The patient had difficulty in swallowing. Forty c.c. of serum were given intravenously, and repeated four hours later; there was no reaction from the serum. September 25 , the edema was subsiding. September 28 , the edema had about disappeared. The same treatment was continued with subsidence of all symptoms. The wound at present is rapidly granulating.

Comment.-This was the most severe infection, and the only one producing any delirium. In this case infection 
was not combated until injections of anthrax serum were used, after which there was a general subsidence of symptoms.

\section{SUMMARY}

1. The source of infection was not definitely determined. In two cases, cultures of toilet articles, especially shaving brushes, were made, with no growth. Unfortunately the others were destroyed before we could get them. All the patients wore chinstraps of leather. One had slept, using his haversack as a pillow. Another used a leather seat on the train as a bed. None had been around animals of any kind.

2. The operations were performed under local anesthesia, without any attempt to control hemorrhage, as loss of blood from the site of infection was advisable. Cauterization and injection of 5 per cent. phenol into the cellular tissue, followed by continuous alcohol dressings, are indispensable. Skin grafting decreased the period of convalescence by weeks.

3. Antianthrax serum was of benefit in one case. It was used in only two of our cases, being discontinued in one after rather severe reaction.

4. Guinea-pigs died within thirty-six hours after inoculation.

\section{ANTHRAX AT CAMP DODGE, IOWA

REPORT OF THREE CASES, WITH BACTERIOLOGIC AND BLOOD STUDIES *}

CARL G. DENNETT, M.D. (SACo, MAINE)

First Lieutenant, M. C., U. S. Army

CAMP DODGE, DES MOINES, IOWA

The literature of anthrax reveals surprisingly meager attention paid to blood culture and cell count studies in this infection. The results of such studies in the cases here recorded may therefore prove of interest. The three soldiers of this camp affected with anthrax were admitted to the base hospital between Sept. 6 and Sept. 19, 1918. Of these, one died and two recovered. Two days previous to the earlier date a soldier had died immediately on entering the receiving ward, in whom the necropsy showed extensive intestinal anthrax.

\section{REPORT OF CASES}

CASE 1.-Private A. C., white, aged 30, admitted, Sept. 12, 1918, had entered the service one week before. Before entering the service, he had been a car repairer. September 6 , he noticed a pimple on the left cheek which was slightly painful. Three days later the pain was considerable and the lesion was discharging bloody serum. A few days before the appearance of the furuncle he had used a new shaving brush. Examination revealed a rather superficial induration the size of a dollar situated on the left cheek, $5 \mathrm{~cm}$. from the angle of the mouth, with a dark red central eschar the size of a finger tip, discharging a serosanguineous fluid. The glands of the neck were not enlarged. The temperature was 98 , the pulse 78 , and respiration 22 . Two $\mathrm{cm}$. of 5 per cent. phenol solution were injected around the areola and 50 c.c. of pneumococcus serum (Rockefeller) given intravenously. Forty-eight c.c. of the serum were similarly given on the following day. This serum was administered in this and the other two cases by the attending ward surgeons because it was the only horse serum available, antianthrax serum not being immediately obtainable. Two days later the swelling began to subside and at the end of two weeks had disappeared. A mild conjunctival and nasal catarrh appeared eight days after the administration of the serum, which lasted

* From the Laboratory of the Base Hospital. a few days, followed by a general anaphylactic urticaria which persisted for a week. The temperature never rose above 99.6. Smears and cultures from the lesion were positive on the first two days and negative on the five succeeding examinations (Table 3). Daily blood counts revealed no leukocytosis (Table 1). The anthrax bacillus was demonstrated in culture of the shaving brush bristles, but this is not of value, as the patient had used the brush after the development of the lesion. Daily blood cultures were negative (Table 1).

CASE 2.-Private P. B., white, aged 21, admitted, Sept. 11, 1918, had been a farmer before entering the service, but had not handled animals with discharging sores. He had used his present shaving brush two months. September 8 , he experienced frontal headache and on the following day noticed a pimple on the left side of the neck about midway between the angle of the jaw and the chin. The swelling about the lesion began to increase at once, and there was pain which radiated down the left side of the chest and was aggravated by coughing. On admission the patient stated that he had vomited earlier in the day, and complained of severe headache and left pectoral pain aggravated by coughing and on deep breathing. The temperature was 101, the pulse 112 , and respiration 26 . On the left side of the neck immediately below the middle of the border of the inferior maxilla was an indurated area about the size of a quarter in the center of which an eschar with irregular edges and about the size of a dime was seen. Several vesicles surrounded the eschar and a serosanguineous fluid exuded from under it. An inflammatory and edematous areola surrounded the lesion and extended to the zygoma above and the clavicle below. This spread within a few hours to the hairline above and the level of the nipple below. There was also some extension to the right side of the neck. Except for a few moist râles over the left base, the lungs were negative. A smear from the discharge on admission showed the presence of the anthrax bacillus, and a pure growth was obtained on culture (Table 3 ). Three hours after admission, serum treatment was begun. Pneumococcus' serum was given as follows :

September 11: 2:30 p. m., 20 c.c. subcutaneously in the pectoral region; 7 p. m., 30 c.c. subcutaneously in the pectoral region.

September 12: 11:30 a. m., 50 c.c. subcutaneously in the gluteal region; $6: 30$ p. m., 50 c.c. subcutaneously in the gluteal region.

September $13: 10: 30$ a. m., 85 c.c. intravenously.

On the evening of September $11,0.5$ c.c. of a 5 per cent. phenol solution was injected around the margin of the indurated area. The edema and inflammation began to subside, September 12, and had disappeared on the 14th. A few days later the induration and discharge were also gone, leaving a dry, black eschar, which had entirely healed, September 26. Slight cervical glandular swelling persisted until the patient's discharge, October 6 . Blood cultures were positive for B. anthracis, September 11, 12 and 13, and negative thereafter. This, together with the daily white cell count, is shown in Table 1.

CASE 3.-Recruit G. N., white, aged 29 , admitted, Sept. 19 , 1918, had entered the service two weeks before. He had been a farmer. Some of the cattle he had handled had had "pinkeye," but were not otherwise affected. September 16 while on the drill field, he noticed a papule on the right side of the neck near the angle of the jaw. On the following day he pricked the pimple, drawing blood and pus. On the next day he cut the sore while shaving with a razor which he had purchased at the regimental exchange ten days before. Soon after this the tissues around the lesion began to swell. On admission the patient complained of headache, and alternating hot and cold sensations. The temperature was 98 the pulse 78, and respiration 20 . An indurated, slightly inflamed area about $7 \mathrm{~cm}$. in diameter, with a central ulceration containing seropurulent fluid and covered with dried coagulum, was situated at the angle of the lower jaw on the right side. The cervical glands were enlarged. Moist râles were heard at both pulmonary apexes, and there was slight tenderness in the lower abdomen. A smear and culture made 